\title{
Catalytic Oxidation of Primary C-H Bonds in Alkanes with Bioinspired Catalysts
}

\author{
Valeria Dantignana, Anna Company*, and Miquel Costas*
}

\begin{abstract}
Catalytic oxidation of primary $\mathrm{C}-\mathrm{H}$ bonds of alkanes with a series of iron and manganese catalysts is investigated. Products resulting from oxidation of methylenic sites are observed when hexane (S1) is used as model substrate, while corresponding primary $\mathrm{C}-\mathrm{H}$ bonds remain unreactive. However, by using 2,2,3,3-tetramethylbutane (S2) as model substrate, which only contains primary alkyl C-H bonds, oxidation takes place catalytically using a combination of hydrogen peroxide, a manganese catalyst and acetic acid as co-catalyst, albeit with modest yields (up to 4.4 TON). Complexes bearing tetradentate aminopyridine ligands provide the best yields, while a related pentadentate ligand provides smaller product yields. The chemoselectivity of the reaction is solvent dependent. Carboxylic acid $\mathbf{2 b}$ is observed as major product when the reaction takes place in acetonitrile, because of the facile overoxidation of the first formed alcohol product $\mathbf{2 a}$. Instead the corresponding primary alcohol $\mathbf{2} \mathbf{a}$ becomes dominant in reactions performed in 2,2,2-trifluoroethanol (TFE). Polarity reversal of the hydroxyl moiety arising from the strong hydrogen bond donor ability of the latter solvent accounts for the unusual product chemoselectivity of the reaction. The significance of the current results in the context of light alkane oxidation is discussed.
\end{abstract}

Keywords: Alkane oxidation · Hydrogen peroxide · Iron · Manganese $\cdot$ Primary C-H bonds

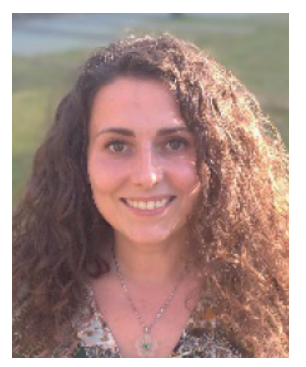

Valeria Dantignana obtained her MSc in Chemistry in 2016 at 'La Sapienza' University in Rome. In 2016 she took part in a Marie Skłodowska-Curie ITN Action (NoNoMeCat project) and started her PhD in the QBIS-CAT group at the University of Girona, under the supervision of Dr. Miquel Costas and Dr. Anna Company. Her PhD work is mainly focused on $\mathrm{C}-\mathrm{H}$ bond oxidation catalyzed by bioinspired complexes and investigation of the reactivity of high valent oxoiron compounds.

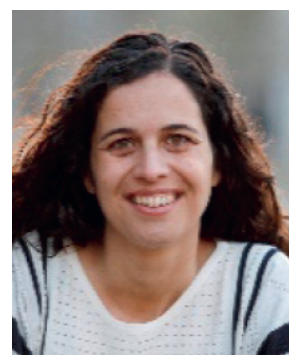

Anna Company obtained her BSc in Chemistry in 2004 and her PhD in Chemistry in 2008 at the University of Girona (UdG, Catalonia). She then joined the group of Prof. Driess at the TU Berlin (Germany) as a 2-year postdoctoral researcher with a Marie Curie Intra-European Fellowship. She returned to the UdG in 2012 as a 'Ramón y Cajal' fellow and since April 2018 she is appointed as an Associate Professor. Anna currently leads a research team at IQCC-UdG working on the activation of small molecules and the characterization of high-valent species relevant in biology and catalysis. Among other awards, she was the recipient of the 2015 Clara Immerwahr Award granted by the German Cluster of Excellence UniCat and the 2019 ICREA Academia Award by Generalitat de Catalunya.

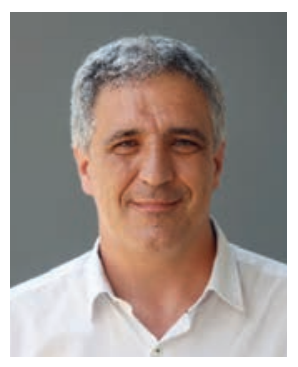

Miquel Costas pursued $\mathrm{PhD}$ studies in the group of Prof. A Llobet at the University of Girona (UdG). Research work during his $\mathrm{PhD}$ involved scientific stays at Texas A\&M (Prof. D. Barton, 1996), and in Basel (Prof. A. Zuberbüiehler, 1998). He then moved to the group of Prof. L. Que, Jr, at the University of Minnesota. He returned to Spain and was appointed as Professor in 2003. Since 2006, he is group leader in the IQCC of UdG. His research interests involve biologically inspired design of inorganic reactivity and catalysis and supramolecular chemistry. He has received the ICREA Academia Award (2008, 2013 and 2018), the Prize for Excellence in Research of the RSEQ (2014) and the Syngenta Lectureship Award (2018). He has been invited professor in the University of Utrecht (2014) and in the University of Paris Diderot (2019).

\section{Introduction}

The oxidation of alkane $\mathrm{C}-\mathrm{H}$ bonds represents a relevant research topic because it converts abundant and economic hydrocarbons into valuable compounds for further chemical elaboration. ${ }^{[1-3]}$ The main challenges of the reaction are the poorly reactive nature of alkane $\mathrm{C}-\mathrm{H}$ bonds, rooted in their high bond dissociation energy and non-polar character, the control of site selectivity in substrates containing non-equivalent $\mathrm{C}-\mathrm{H}$ bonds, and limiting overoxidation of the first formed oxidation products, since alcohols are more reactive than alkane $\mathrm{C}-\mathrm{H}$ bonds. Non-porphyrinic iron and manganese coordination complexes reproducing basic struc- 
tural aspects of non-heme oxygenases can form high valent metaloxo species with the competence to oxidize aliphatic $\mathrm{C}-\mathrm{H}$ bonds in a selective manner under mild experimental conditions. ${ }^{[4-14]}$ Oxidation of secondary and tertiary $\mathrm{C}-\mathrm{H}$ bonds is well documented for a number of these type of catalysts, and competitive oxidation of these two type of bonds is customarily observed in substrates containing the two types. ${ }^{[15-32]}$ In contrast, oxidation of primary aliphatic $\mathrm{C}-\mathrm{H}$ bonds of alkanes has been only seldom observed. The reaction is particularly interesting when applied to light alkanes, which stand as one of the most difficult classes of substrates in aliphatic $\mathrm{C}-\mathrm{H}$ oxidation. For example, Shul'pin and co-workers reported the oxidation of unactivated alkanes catalyzed by a dinuclear iron complex $\left(\left[\mathrm{Fe}_{2}(\mathrm{HPTB})(\mu-\mathrm{OH})\left(\mathrm{NO}_{3}\right)_{2}\right]\right.$ $\left.\left(\mathrm{NO}_{3}\right)_{2} \cdot \mathrm{CH}_{3} \mathrm{OH} \cdot 2 \mathrm{H}_{2} \mathrm{O}\right)$ and pyrazinic acid as co-catalyst, in combination with hydrogen peroxide. ${ }^{[33]}$ In particular the authors were able to oxidize methane (TON $=4)$ and ethane (TON =21) obtaining the corresponding hydroperoxides as the main products. In subsequent works, the author reported also a study of the oxygenation of alkanes catalyzed by different iron complexes. ${ }^{[34,35]} \mathrm{Up}$ to 41 TON was obtained in the oxidation of methane, in the presence of pyrazinic acid. In the above mentioned works, the hydroxyl radical and ferroxy radical species were considered as possible oxidants. Stronger evidence of a possible metal-based oxidation was reported by Sorokin and co-workers, who described the first example of an oxoiron(IV) complex capable of oxidizing strong $\mathrm{C}-\mathrm{H}$ bonds, namely $\left[(\mathrm{TPP})(\mathrm{m}-\mathrm{CBA}) \mathrm{Fe}^{\mathrm{IV}}(\mu-\mathrm{N}) \mathrm{Fe}^{\mathrm{IV}}(\mathrm{O})\left(\mathrm{TPP}^{\bullet+}\right)\right]^{-}{ }^{-[36]}$ Using the $\left[(\mathrm{TPP}) \mathrm{Fe}^{\mathrm{III}}(\mu-\mathrm{N}) \mathrm{Fe}^{\mathrm{IV}}(\mathrm{TPP})\right]$ catalyst supported on silica and $m$-chloroperbenzoic acid as oxidant, $43.5 \%$ yield of formic acid (with respect to $m$-chloroperbenzoic acid) was obtained in the oxidation of methane (Fig. 1, top). Of interest, the authors used ${ }^{13} \mathrm{C}$-methane to unambiguously demonstrate that formic acid is formed by the oxidation of methane. ${ }^{[37]}$ Recently, Itoh and co-workers reported the oxidation of primary $\mathrm{C}-\mathrm{H}$ bonds of 2,2,3,3-tetramethylbutane (10\% yield of alcohol product with respect to the iron(III) content), achieved using a monomeric oxoiron(IV) porphyrin cation radical compound $\left(\left[\mathrm{Fe}^{\mathrm{IV}}(\mathrm{O})\left(\mathrm{TMP}^{\bullet+}\right)\right.\right.$ (Cl)]). ${ }^{[38]}$ This compound was also shown capable of oxidizing the

Fig. 1. Oxidation of light alkanes with [(TPP)Fe $e^{\text {III }}(\mu-\mathrm{N}) \mathrm{Fe}^{\mathrm{IV}}$ (TPP)] (top) and $\left[\mathrm{Fe}^{\mathrm{III}}\left(\mathrm{Me}_{3} \text { tacn) }(\mathrm{R}-\mathrm{acac}) \mathrm{Cl}\right]^{+}\right.$ (bottom). methylenic site of butane. Moreover, non-heme model complexes that could oxidize light alkanes were reported. In particular, Que and co-workers described the oxidation of butane with a putative oxoiron(IV) species, generated by the reaction of $\left[\mathrm{Fe}^{\mathrm{II}}\left(\mathrm{Tp}^{\mathrm{Ph} 2}\right)\right.$ $\left.\left(\mathrm{O}_{2} \mathrm{CC}(\mathrm{O}) \mathrm{R}\right)\right]$ with molecular oxygen, ${ }^{[39]}$ and Che and co-workers reported the catalytic oxidation of ethane and propane with a mononuclear ferric complex $\left(\left[\mathrm{Fe}^{\mathrm{II}}\left(\mathrm{Me}_{3} \mathrm{tacn}\right)(\mathrm{R}-\mathrm{acac}) \mathrm{Cl}\right]^{+}\right)$and oxone (Fig. 1, bottom). ${ }^{[40]}$

In this work, we sought to investigate the ability of iron and manganese complexes bearing non-porphyrinic ligands to catalyze the oxidation of primary $\mathrm{C}-\mathrm{H}$ bonds of alkanes, as a first step towards the development of catalysts for the oxidation of light alkanes.

\section{Results and Discussion}

\subsection{Reaction Development Employing Hexane (S1) as Model Substrate}

Catalytic oxidation of hexane (S1), taken as model substrate, was investigated first. We screened the catalytic activity of a series of iron and manganese complexes (Fig. 2), which have been previously described as $\mathrm{C}-\mathrm{H}$ oxidation catalysts. The choice included a) an exhaustive family of iron and manganese complexes with tetradentate aminopyridine ligands (1 to $\mathbf{1 6}),{ }^{[4]} \mathrm{b}$ ) bis-bipyridyl manganese complex (17), ${ }^{[41,42]}$ c) bis-picolinate manganese (18) ${ }^{[24,43]}$ as well as corresponding iron (generated in situ) complexes, ${ }^{[44,45]}$ and d) an iron complex with a pentadentate ligand (19). ${ }^{[46]}$ The first group included complexes bearing the pyridylmethyl-triazacyclononane ligand (1 and $\mathbf{2}$ ) and complexes with linear bis-amino-bipyridyl ligands differing in the aliphatic diamine backbone, and also in the electronic and sterically demanding properties of the pyridines (5-16). Complexes 3 and 4, where the methylene groups are deuterated to protect against oxidative degradation, were also explored.[47,48] The choice of oxidants included Oxone ${ }^{\circledR}$, peracetic acid and hydrogen peroxide. All of them have previously found utility in $\mathrm{C}-\mathrm{H}$ oxidation catalysis.
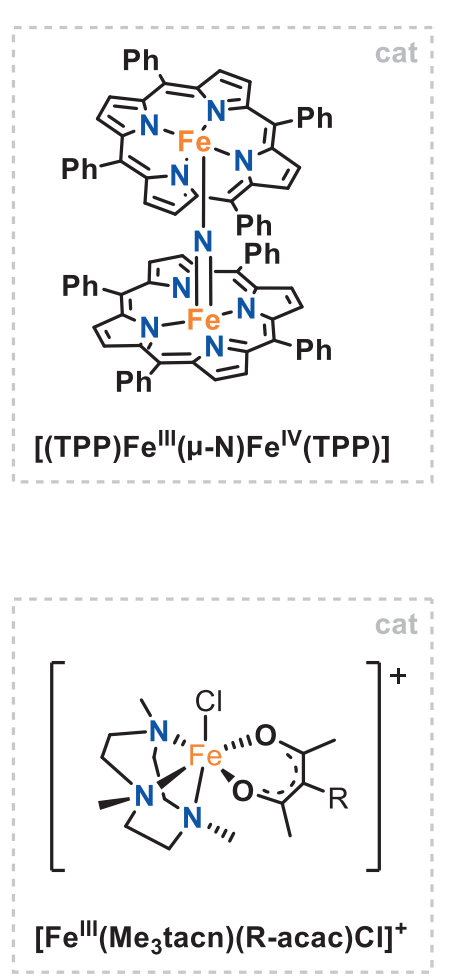
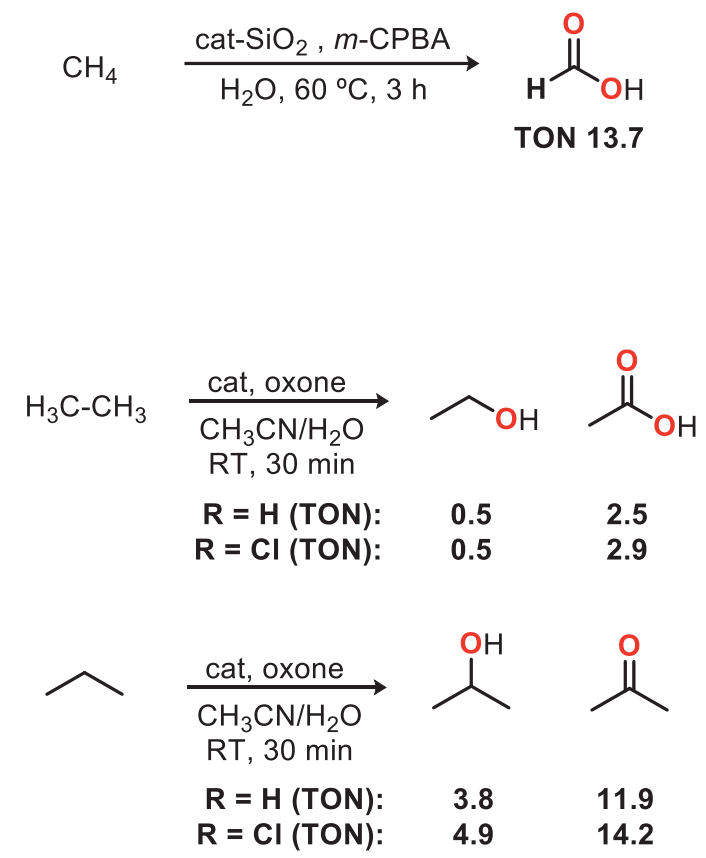<smiles>CCC(=O)O</smiles> 

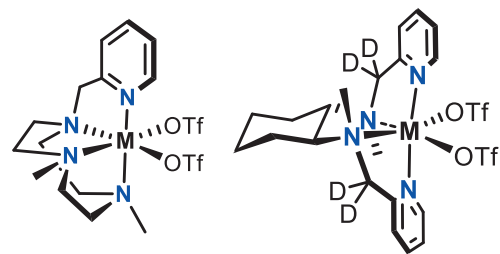

[M(OTf $)_{2}($ Pytacn) $] \quad\left[M(O T f)_{2}\left(\right.\right.$ mcp-d $\left.\left._{4}\right)\right]$ $M=F e(1), M n(2) \quad M=F e ~(3), M n(4)$

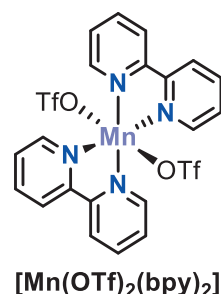

(17)
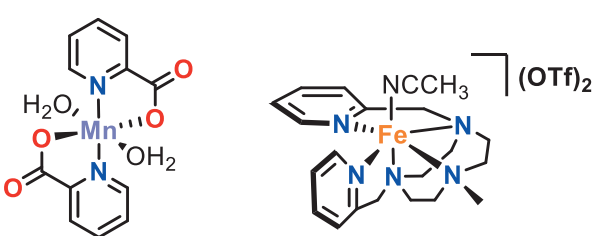

$\left[\mathrm{Mn}(\mathrm{pic})_{2}\left(\mathrm{H}_{2} \mathrm{O}\right)_{2}\right]$

(18)

Fig. 2. Catalysts employed in this work.

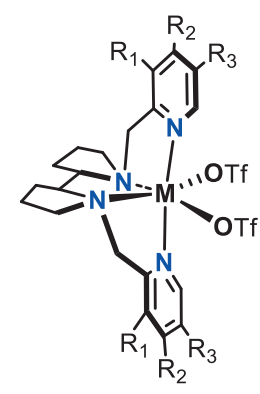

[M(OTf $)_{2}\left({ }^{X}\right.$ pdp)] $\mathrm{M}=\mathrm{Fe}, \mathrm{Mn}$

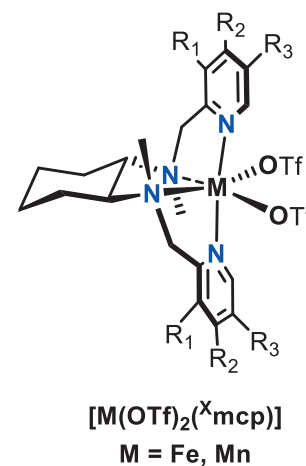

\begin{tabular}{|c|c|c|c|}
\hline & $\mathbf{R}_{\mathbf{1}}$ & $\mathbf{R}_{\mathbf{2}}$ & $\mathbf{R}_{\mathbf{3}}$ \\
\hline $\mathrm{Fe}(\mathrm{OTf})_{2}(\mathrm{pdp})(5)$ & $\mathrm{H}$ & $\mathrm{H}$ & $\mathrm{H}$ \\
\hline $\operatorname{Mn}(O T f)_{2}(p d p)(6)$ & $\mathrm{H}$ & $\mathrm{H}$ & $\mathrm{H}$ \\
\hline $\mathrm{Fe}(\mathrm{OTf})_{2}(\mathrm{mcp})(7)$ & $\mathrm{H}$ & $\mathrm{H}$ & $\mathrm{H}$ \\
\hline $\operatorname{Mn}(\mathrm{OTf})_{2}(\mathrm{mcp})(8)$ & $\mathrm{H}$ & $\mathrm{H}$ & $\mathrm{H}$ \\
\hline $\mathrm{Fe}(\mathrm{OTf})_{2}\left({ }^{\mathrm{dMM}} \mathrm{pdp}\right)(9)$ & $\mathrm{Me}$ & $\mathrm{MeO}$ & $\mathrm{Me}$ \\
\hline$M n(O T f)_{2}\left({ }^{d M M} p d p\right)(10)$ & $\mathrm{Me}$ & $\mathrm{MeO}$ & $\mathrm{Me}$ \\
\hline $\mathrm{Fe}(\mathrm{OTf})_{2}\left({ }^{\mathrm{dMM}} \mathrm{mcp}\right)(11)$ & $\mathrm{Me}$ & $\mathrm{MeO}$ & $\mathrm{Me}$ \\
\hline$M n(O T f)_{2}\left({ }^{d M M} \mathrm{mcp}\right)(12)$ & $\mathrm{Me}$ & $\mathrm{MeO}$ & $\mathrm{Me}$ \\
\hline $\mathrm{Fe}(\mathrm{OTf})_{2}\left({ }^{\mathrm{Cl}} \mathrm{pdp}\right)(13)$ & $\mathrm{H}$ & $\mathrm{Cl}$ & $\mathrm{H}$ \\
\hline $\mathrm{Mn}(\mathrm{OTf})_{2}\left({ }^{\mathrm{Cl}} \mathrm{pdp}\right)(14)$ & $\mathrm{H}$ & $\mathrm{Cl}$ & $\mathrm{H}$ \\
\hline $\mathrm{Fe}(\mathrm{OTf})_{2}\left({ }^{\text {TIPS }}\right.$ pdp) (15) & $\mathrm{H}$ & $\mathrm{H}$ & $\mathrm{Si}(\mathrm{iPr})_{3}$ \\
\hline $\mathrm{Mn}(\mathrm{OTf})_{2}\left({ }^{\mathrm{TIPS}} \mathrm{pdp}\right)(16)$ & $\mathrm{H}$ & $\mathrm{H}$ & $\mathrm{Si}(\mathrm{iPr})_{3}$ \\
\hline
\end{tabular}

We first studied the oxidation of $\mathbf{S 1}$ (1 equiv.) using Oxone ${ }^{\circledR}$ as oxygen atom donor ( 0.2 equiv. single addition as solid $)$ and $\left[\mathbf{M}(\mathbf{O T f})_{2}(\text { Pytacn)] (1, 2), [Mn(OTf })_{2}(\mathbf{b p y})_{2}\right]$ (17) and $\left[\mathrm{Mn}(\mathbf{p i c})_{2}\left(\mathbf{H}_{2} \mathbf{O}\right)_{2}\right](\mathbf{1 8})$ as catalysts $(1 \mathrm{~mol} \%)$ in acetonitrile solution at room temperature. No oxidation products were observed in any of these reactions. The use of hydrogen peroxide $(0.2$ equiv. added via syringe pump over 30 mins) provided a different outcome. No oxidized products were observed in reactions performed using manganese catalysts bearing bidentate ligands $\mathbf{1 7}$ (entry 1, Table 1) and $\mathbf{1 8}$ (entry 4, Table 1). However, when a combination of $\mathrm{Fe}(\mathrm{OAc})_{2}$ and picolinic acid was used to generate in situ the desired iron catalyst, ${ }^{[49]}$ the reaction proceeded in modest yields (6\%, see supporting information for details, Table S1) providing a mixture of 2-hexanol (1a), 3-hexanol (1b) and the corresponding ketone products (1c and 1d). Unfortunately, no products resulting from oxidation of the primary $\mathrm{C}-\mathrm{H}$ bonds were detected. As a general trend, improved yields were obtained when complexes bearing tetradentate aminopyridine ligands, 1, 2 (entries 7 and 10, Table 1) and 7, 8 (entries 13 and 16, Table 1), were employed as catalysts; and up to $27 \%$ combined yield (4.3 product TON defined as $\Sigma$ [oxidation products]/[catalyst]) of products resulting from oxidation of methylenic sites was obtained in the case of 7 (entry 13, Table 1).

The results could be further improved by performing the reactions in the presence of acetic acid $(\mathrm{AcOH}) .{ }^{[51,52]}$ In line with the results obtained in the absence of acetic acid, complexes 7 and 8 (entries 14 and 17, Table 1) were the most efficient catalysts exhibiting combined yields of alcohol and ketone products of $32 \%$ for iron and $40 \%$ for manganese, in all cases resulting from methylene oxidation. Moreover, iron and manganese complexes bearing the deuterated mcp ligand (3 and 4) were also tested. As pseudobenzylic $\mathrm{C}-\mathrm{H}$ bonds are susceptible to oxidation, deuteration of these positions was performed to avoid the possible catalyst self-degradation by pseudobenzylic oxidation. However, no improvement in the yield was observed with the deuterated complexes (entries 19 and 21, Table 1).

Finally, we tested the use of peracetic acid (PAA) as terminal oxidant (Table 1). This oxidant is effective with all the catalysts tested, and with the single exception of $\mathbf{8}$ (entry 18, Table 1) it provided the highest yield of oxidation products for the rest of the catalysts. The best results in terms of product TON were obtained with 7 (entry 15, Table 1), which provided a mixture of alcohols and ketones resulting exclusively from methylene oxidation in $39 \%$ yield (with respect to the oxidant). Again, products resulting from methyl oxidation were not observed.

\subsection{Reaction Development Employing 2,2,3,3-Tetramethylbutane as Model Substrate}

While the lack of methyl oxidation products was disappointing, it aligns with previous reports where the oxidation of S1 has been studied. We considered that the lack of primary $\mathrm{C}-\mathrm{H}$ oxidation products may arise from the lack of oxidation ability of the metal-oxidants generated in these reactions (presumably high valent metal-oxos) to break via hydrogen atom transfer (HAT) these particularly strong $\mathrm{C}-\mathrm{H}$ bonds. Alternatively, it may reflect a much faster and competitive oxidation reactivity against secondary over primary $\mathrm{C}-\mathrm{H}$ bonds. In order to address this question we studied the oxidation of 2,2,3,3-tetramethylbutane (S2), which contains only primary $\mathrm{C}-\mathrm{H}$ bonds. Furthermore, due to its solid physical state and solubility in conventional solvents, the use of this substrate is technically much simpler than studying the oxidation of gaseous light alkanes, such as methane, ethane or propane.

Oxidation of $\mathbf{S 2}$ was initially studied using complexes $\mathbf{7}$ and 8 as catalysts ( $1 \mathrm{~mol} \%$ ) and hydrogen peroxide ( 0.2 equiv., combined with acetic acid) or peracetic acid ( 0.2 equiv.) as oxidant in acetonitrile solution, at room temperature (Table 2). The reactions yielded primary alcohol (2a) as minor product (1\% with respect to the oxidant, which corresponds to 0.2 equiv. of $\mathbf{2 a}$ / equiv. of catalyst) and the corresponding carboxylic acid (2b) as the major reaction product (7-8\% with respect to the oxidant, which translates to $\sim 0.5$ equiv. 2 b/equiv. of catalyst). It should be borne in mind that according to stoichiometry each equiv. of $\mathbf{2 b}$ requires 3 equiv. of hydrogen peroxide) (entries 1 and 5 , Table 2). Thus, the reaction takes place but the amount of oxidized product is substoichiometric with respect to the catalyst. Performing the reaction in deuterated acetonitrile did not improve product yields, discounting the solvent as a competitive substrate. However, an improved use of the oxidant was attained by using larger concentrations of substrate. For example, increasing the substrate concentration fivefold, oxidation products 2a and $\mathbf{2 b}$ were obtained in $4 \%$ and $12 \%$ yields (respectively, 0.8 equiv. of $\mathbf{2 a}$ and 0.8 equiv. of $\mathbf{2} \mathbf{b}$ per equiv. of catalyst) using $\mathbf{7}$ (entry 3 , Table 2). 
Table 1. Oxidation of hexane (S1) with hydrogen peroxide (combined with and without acetic acid) or peracetic acid.

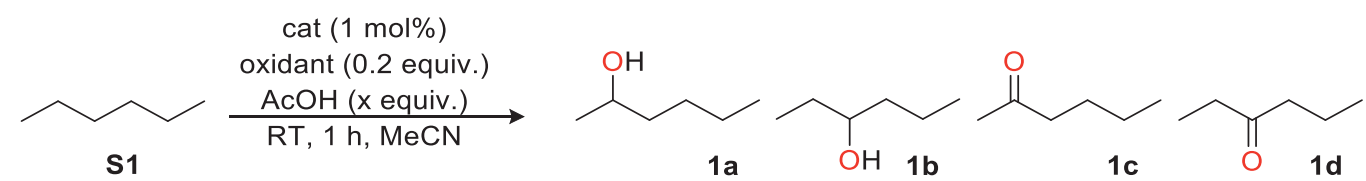

\begin{tabular}{|c|c|c|c|c|c|c|}
\hline Entry & Catalyst & Oxidant & $\begin{array}{c}\text { AcOH } \\
\text { (equiv.) }\end{array}$ & $\begin{array}{l}\text { Yield [\%] } \\
\quad 1 \mathrm{a}+1 \mathrm{~b}\end{array}$ & $\begin{array}{l}\text { Yield [\%] } \\
1 \mathrm{c}+1 \mathrm{~d}\end{array}$ & $\begin{array}{c}\text { Product } \\
\text { TON }^{\mathrm{b}}\end{array}$ \\
\hline 1 & 17 & $\mathrm{H}_{2} \mathrm{O}_{2}$ & 0 & 0 & 0 & 0 \\
\hline 2 & & $\mathrm{H}_{2} \mathrm{O}_{2}$ & 2 & 0 & 0 & 0 \\
\hline 3 & & PAA & 0 & 4 & 15 & 2.3 \\
\hline 4 & 18 & $\mathrm{H}_{2} \mathrm{O}_{2}$ & 0 & 0 & 0 & 0 \\
\hline 5 & & $\mathrm{H}_{2} \mathrm{O}_{2}$ & 2 & 0 & 0 & 0 \\
\hline 6 & & PAA & 0 & 4 & 17 & 2.5 \\
\hline 7 & 1 & $\mathrm{H}_{2} \mathrm{O}_{2}$ & 0 & 4 & 5 & 1.3 \\
\hline 8 & & $\mathrm{H}_{2} \mathrm{O}_{2}$ & 2 & 4 & 7 & 1.5 \\
\hline 9 & & PAA & 0 & 6 & 15 & 2.7 \\
\hline 10 & 2 & $\mathrm{H}_{2} \mathrm{O}_{2}$ & 0 & 1 & 7 & 0.9 \\
\hline 11 & & $\mathrm{H}_{2} \mathrm{O}_{2}$ & 2 & 3 & 0 & 0.6 \\
\hline 12 & & PAA & 0 & 2 & 12 & 1.6 \\
\hline 13 & 7 & $\mathrm{H}_{2} \mathrm{O}_{2}$ & 0 & 16 & 11 & 4.3 \\
\hline 14 & & $\mathrm{H}_{2} \mathrm{O}_{2}$ & 2 & 16 & 16 & 4.8 \\
\hline 15 & & PAA & 0 & 18 & 21 & 5.7 \\
\hline 16 & 8 & $\mathrm{H}_{2} \mathrm{O}_{2}$ & 0 & 4 & 6 & 1.4 \\
\hline 17 & & $\mathrm{H}_{2} \mathrm{O}_{2}$ & 2 & 16 & 24 & 5.6 \\
\hline 18 & & PAA & 0 & 2 & 32 & 3.6 \\
\hline 19 & 3 & $\mathrm{H}_{2} \mathrm{O}_{2}$ & 2 & 14 & 14 & 4.2 \\
\hline 20 & & PAA & 0 & 17 & 20 & 5.4 \\
\hline 21 & 4 & $\mathrm{H}_{2} \mathrm{O}_{2}$ & 2 & 10 & 6 & 2.6 \\
\hline 22 & & PAA & 0 & 3 & 28 & 3.4 \\
\hline
\end{tabular}

With respect to the oxidant, determined by GC-FID against an internal standard. Yields are calculated considering that 2 equiv. of oxidant are necessary for the formation of the ketone products (1c and 1d). ${ }^{b}$ Defined as $\Sigma$ [oxidation products]/[catalyst].

While high valent metal oxo species are accepted to be the $\mathrm{C}-\mathrm{H}$ oxidizing species in reactions catalyzed by this class of complexes, we also considered the possibility that the observed reactivity may be due to the involvement of hydroxyl radicals. In order to address this question, an experiment was performed with complex 19. MePy,tacn is a neutral, pentadentate aminopyridine ligand. ${ }^{[46]}$ The corresponding complex has one available coordination site for peroxide activation. This class of complexes activate hydrogen peroxide via an homolytic $\mathrm{O}-\mathrm{O}$ cleavage ${ }^{[31,32,52]}$ instead of producing hydroxyl radicals, and because of that it was devised as an informative tool to estimate the viability of such a process. Using the best reaction conditions found with 7 (19/ AcOH/oxidant/substrate ratios 1/200/20/500), product $\mathbf{2 a}$ and $\mathbf{2 b}$ were obtained in $2 \%$ and $3 \%$ yields (entry 9 , Table 2 ), which correspond to a product TON of 0.6 ( 0.4 equiv. of $\mathbf{2 a}$ and 0.2 equiv. of $\mathbf{2 b}$ per equiv. of catalyst). The substantially reduced yields, when compared with catalysts $\mathbf{7}$ and $\mathbf{8}$ under analogous condi- tions (entries 3 and 7, Table 2), suggest that substrate oxidation via the homolytic $\mathrm{O}-\mathrm{O}$ cleavage path, if present, may be a minor contributor to the reaction.

With the aim to improve the preliminary results obtained, we evaluated the effect of different electronic or steric properties of the ligand, as well as of a different diamine backbone, on the outcome of the oxidation of $\mathbf{S 2}$ (Table 3). The screening revealed that the change of the cyclohexyldiamine (mcp ligand) by the bipyrrolidine backbone (pdp ligand) led to a significant increase of the yield, with maximum combined values of $26 \%$ and $31 \%$, respectively, for 5 (entry 1, Table 3) and $\mathbf{6}$ (entry 8, Table 3) where $\mathbf{2 b}$ was the largely dominant product (1.6-1.9 TON of 2b). Conversely, electronic or steric modification of the nature of the catalysts did not play a relevant role (entries 3-6 and 10-13, Table 3). Increasing the amount of oxidant employed (from 0.2 to 1 equiv., entries 2 and 9 in Table 3 and Table S2 in supporting information) translated into an increase of TON; up to 3.4 and 4.4 

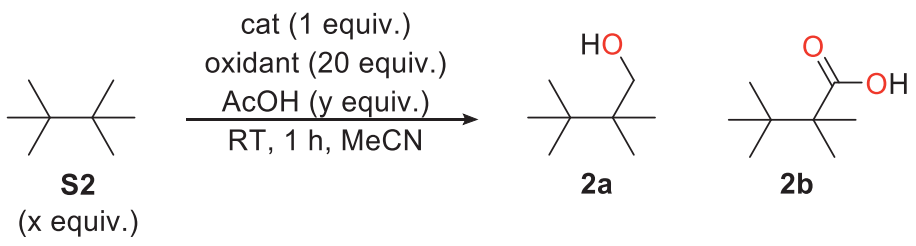

Table 2. Oxidation of 2,2,3,3-tetramethylbutane (S2) with hydrogen peroxide (combined with acetic acid) or peracetic acid.

\begin{tabular}{|c|c|c|c|c|c|c|c|}
\hline Entry & Catalyst & $\begin{array}{c}\text { S2 } \\
\text { (equiv.) }\end{array}$ & Oxidant & $\begin{array}{c}\text { AcOH } \\
\text { (equiv.) }\end{array}$ & $\begin{array}{c}\text { Yield } \\
{[\%]^{\mathrm{a}} \mathbf{2 a}}\end{array}$ & $\begin{array}{c}\text { Yield } \\
{[\%]^{\mathrm{a}} \mathbf{2 b}}\end{array}$ & $\begin{array}{c}\text { Product } \\
\text { TON }^{b}\end{array}$ \\
\hline 1 & 7 & 100 & $\mathrm{H}_{2} \mathrm{O}_{2}$ & 200 & 1 & 7 & 0.7 \\
\hline 2 & & 200 & $\mathrm{H}_{2} \mathrm{O}_{2}$ & 200 & 2 & 8 & 0.9 \\
\hline 3 & & 500 & $\mathrm{H}_{2} \mathrm{O}_{2}$ & 200 & 4 & 12 & 1.6 \\
\hline 4 & & 100 & PAA & 0 & 1 & 9 & 0.8 \\
\hline 5 & 8 & 100 & $\mathrm{H}_{2} \mathrm{O}_{2}$ & 200 & 1 & 8 & 0.7 \\
\hline 6 & & 200 & $\mathrm{H}_{2} \mathrm{O}_{2}$ & 200 & 2 & 14 & 1.3 \\
\hline 7 & & 500 & $\mathrm{H}_{2} \mathrm{O}_{2}$ & 200 & 4 & 6 & 1.2 \\
\hline 8 & & 100 & PAA & 0 & 0 & 9 & 0.6 \\
\hline 9 & 19 & 500 & $\mathrm{H}_{2} \mathrm{O}_{2}$ & 200 & 2 & 3 & 0.6 \\
\hline
\end{tabular}

aWith respect to the oxidant, determined by GC-FID against an internal standard. Yields are calculated considering that 3 equiv. of oxidant are necessary for the formation of the carboxylic acid product (2b). Yield $\mathbf{2 a}$ calculated with response factor of $\mathbf{2} \mathbf{b}$. b Defined as $\Sigma$ [oxidation products]/[catalyst].

TON were obtained respectively with 5 (entry 2, Table 3) and 6 (entry 9, Table 3).

\subsection{Reversal of Chemoselectivity by Employing Fluorinated Alcohol Solvents}

In all the above mentioned reactions, formation of the hydroxylated product $\mathbf{2} \mathbf{a}$ is minimal and instead the major product corresponds to the overoxidized carboxylic acid $\mathbf{2 b}$. In order to modify this chemoselectivity, we performed the reactions in a fluorinated alcohol solvent. These solvents are powerful hydrogen bond donors and strongly interact with hydroxyl moieties, causing a polarity reversal that deactivates adjacent $\mathrm{C}-\mathrm{H}$ bonds against further oxidation. ${ }^{[53-56]}$ Remarkably, the use of TFE led to an important change in the chemoselectivity of the reaction. In the case of the iron catalyst, a moderate reduction in TON was observed upon changing from acetonitrile to TFE (compare entries 1 and 3 with 2 and 4, Table 4). However, the activity of the manganese catalyst was improved (compare entries 5 and 7 with 6 and 8, Table 4). As detailed in Table 4, using standard conditions (6/AcOH/oxidant/ substrate ratios $1 / 200 / 20 / 500$ ), up to $4.4 \mathrm{TON}$ of products were obtained with a $73 \%$ selectivity for the alcohol $\mathbf{2 a}$ (entry 8 , Table 4 ).

\section{Context and Summary}

The results of the study show that iron and manganese complexes bearing tetradentate aminopyridine ligands can oxidize primary alkyl $\mathrm{C}-\mathrm{H}$ bonds in a catalytic manner. While TON should be considered as modest, an analysis of literature precedents indicate that the numbers are in the same order with the state of the art in the field. For example, considering the activity of non-heme model complexes, in the oxidation of ethane Che and co-workers reported a maximum value for total TON of 3.4. ${ }^{[40]}$ Instead, in the oxidation of propane they obtained a maximum value for total TON of 20.4, although oxidation is largely dominant in the secondary $\mathrm{C}-\mathrm{H}$ bonds. In fact, the maximum TON for the formation of propionic acid was 1.3. On the other hand, direct comparison should be taken with care because the experimental conditions and the physical nature of the substrate are different. 2,2,3,3-tetramethylbutane is a solid and the concentration of the solutions of this substrate employed in our reactions are in the order of $0.1-0.5 \mathrm{M}$. On the other hand, under the conditions described by Che and co-workers (6.9 bar of pressure of ethane over a 1:1 solvent mixture of water and acetonitrile), the substrate concentration is not known, but presumably smaller. In addition, oxidation of methyl groups in $\mathbf{S 2}$ is statistically favored over ethane by a 3:1 ratio. Finally, it must be stated that the activity of this class of catalysts falls short when compared with the catalytic oxidation of methane, which is an even more resistant substrate towards oxidation, catalyzed by [(TPP)Fe $\mathrm{Fe}^{\mathrm{III}}(\mu-\mathrm{N})$ $\left.\mathrm{Fe}^{\mathrm{IV}}(\mathrm{TPP})\right]-\mathrm{SiO}_{2}$; in this case the TON reported is about three times higher than the one we reached. ${ }^{[36,37]}$

In conclusion, 5 and $\mathbf{6}(\mathrm{M}=\mathrm{Fe}$ and $\mathrm{Mn})$ catalyze oxidation of primary $\mathrm{C}-\mathrm{H}$ bonds with peroxides. TON unambiguously support catalytic activity, but they are still modest to address light alkane oxidation reactions in a satisfactory manner. Strategies to improve the efficiency in the use of the oxidant, for example by increasing the local concentration of substrate or by designing catalysts that generate more electrophilic metal-oxo oxidants, are required and are currently under exploration.

\section{Experimental Section}

\subsection{Materials}

Reagents and solvents used were of commercially available reagent quality unless otherwise stated. Solvents were purchased from Scharlab, Acros, Fluorochem or Sigma-Aldrich and used without further purification. Hydrogen peroxide, peracetic acid and acetic acid solutions employed in the oxidation reactions were prepared by diluting commercially available hydrogen peroxide $\left(30 \% \mathrm{H}_{2} \mathrm{O}_{2}\right.$ solution in water, Sigma-Aldrich), peracetic acid (35\% peracetic acid solution in diluted acetic acid, Acros Organics) and glacial acetic acid in the desired solvent. Preparation and handling of air-sensitive materials were carried out in an $\mathrm{N}_{2}$ drybox (Jacomex) with $\mathrm{O}_{2}$ and $\mathrm{H}_{2} \mathrm{O}$ concentrations $<1$ ppm. Complexes 1-16, 18 and 19 were prepared following previously described procedures. ${ }^{[46,47,50,57-66]}$ Products $2 \mathbf{2 a}$ and $\mathbf{2 b}$ were prepared according to literature protocols. ${ }^{[67-70]}$ 
Table 3. Oxidation of $\mathbf{S 2}$ with different catalysts.
Table 4. Oxidation of $\mathbf{S 2}$ in acetonitrile or 2,2,2-trifluoroethanol.

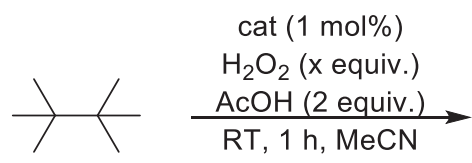

S2

AcOH (2 equiv.)

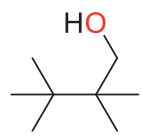

$2 a$

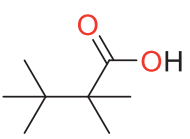

2b

\begin{tabular}{|c|c|c|c|c|c|}
\hline Entry & Catalyst & $\begin{array}{c}\mathrm{H}_{2} \mathrm{O}_{2} \\
\text { (equiv.) }\end{array}$ & $\begin{array}{c}\text { Yield } \\
{[\%]^{\mathbf{a}} \mathbf{2 a}}\end{array}$ & $\begin{array}{c}\text { Yield } \\
{[\%]^{\mathbf{a}} \mathbf{2 b}}\end{array}$ & $\begin{array}{c}\text { Product } \\
\text { TON }^{\mathrm{c}}\end{array}$ \\
\hline & $\begin{array}{c}\text { Iron } \\
\text { catalysts }\end{array}$ & & & & \\
\hline 1 & 5 & 0.2 & 2 & 24 & 2.0 \\
\hline 2 & & $1.0^{\mathrm{b}}$ & $<1$ & 9 & 3.4 \\
\hline 3 & 13 & 0.2 & 1 & 21 & 1.6 \\
\hline 4 & 9 & 0.2 & 1 & 18 & 1.4 \\
\hline 5 & 11 & 0.2 & 1 & 9 & 0.8 \\
\hline 6 & 15 & 0.2 & 1 & 18 & 1.4 \\
\hline \multirow[t]{2}{*}{7} & 3 & 0.2 & 1 & 6 & 0.6 \\
\hline & $\begin{array}{c}\text { Manganese } \\
\text { catalysts }\end{array}$ & & & & \\
\hline 8 & 6 & 0.2 & 2 & 29 & 2.3 \\
\hline 9 & & $1.0^{\mathrm{b}}$ & 1 & 15 & 4.4 \\
\hline 10 & 14 & 0.2 & 1 & 18 & 1.4 \\
\hline 11 & 10 & 0.2 & 1 & 15 & 1.2 \\
\hline 12 & 12 & 0.2 & traces & 0 & $<0.1$ \\
\hline 13 & 16 & 0.2 & 1 & 30 & 2.2 \\
\hline 14 & 4 & 0.2 & 1 & 1 & 0.3 \\
\hline
\end{tabular}

aWith respect to $\mathrm{H}_{2} \mathrm{O}_{2}$, determined by GC-FID against an internal standard. Yields are calculated considering that 3 equiv. of $\mathrm{H}_{2} \mathrm{O}_{2}$ are necessary for the formation of the carboxylic acid product (2b). Yield 2a calculated with response factor of $\mathbf{2 b}$. ${ }^{b}$ Overoxidation products are formed. ${ }^{\circ}$ Defined as $\Sigma$ [oxidation products]/[catalyst].

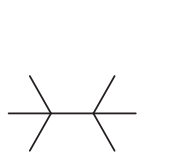

S2

(x equiv.)

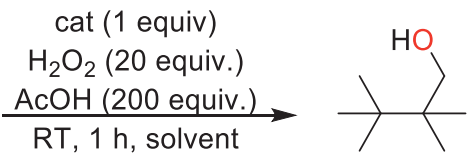

$2 a$

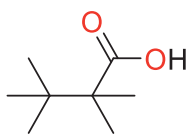

$2 b$

\begin{tabular}{|c|c|c|c|c|c|c|c|}
\hline Entry & Catalyst & Solvent & $\begin{array}{c}\text { S2 } \\
\text { (equiv.) }\end{array}$ & $\begin{array}{c}\text { Yield } \\
{[\%]^{\mathrm{a}} 2 \mathrm{a}}\end{array}$ & $\begin{array}{c}\text { Yield } \\
{[\%]^{\mathrm{a}} 2 \mathrm{~b}}\end{array}$ & $\begin{array}{l}\% \\
2 a\end{array}$ & $\begin{array}{l}\text { Product } \\
\text { TON }^{c}\end{array}$ \\
\hline 1 & 5 & $\mathrm{MeCN}$ & 100 & 2 & 24 & 20 & 2.0 \\
\hline 2 & & TFE & 100 & 6 & 6 & 75 & 1.6 \\
\hline 3 & & $\mathrm{MeCN}$ & 500 & 7 & 33 & 39 & 3.6 \\
\hline 4 & & TFE & $500^{\mathrm{b}}$ & 11 & 9 & 79 & 2.8 \\
\hline 5 & 6 & $\mathrm{MeCN}$ & 100 & 2 & 29 & 17 & 2.3 \\
\hline 6 & & TFE & 100 & 10 & 15 & 67 & 3.0 \\
\hline 7 & & $\mathrm{MeCN}$ & 500 & 5 & 39 & 27 & 3.6 \\
\hline 8 & & TFE & $500^{\mathrm{b}}$ & 16 & 18 & 73 & 4.4 \\
\hline
\end{tabular}

aWith respect to $\mathrm{H}_{2} \mathrm{O}_{2}$, determined by GC-FID against an internal standard. Yields are calculated considering that 3 equiv. of $\mathrm{H}_{2} \mathrm{O}_{2}$ are necessary for the formation of the carboxylic acid product (2b). Yield $2 \mathbf{2 a}$ calculated with response factor of $\mathbf{2 b}$. ${ }^{b}$ Overoxidation products are formed; substrate not totally dissolved. 'Defined as $\Sigma$ [oxidation products]/[catalyst]. 


\subsection{Instrumentation}

Oxidation products were identified by comparison of their GC retention times and GC-MS with those of authentic compounds. GC analyses were performed with an Agilent 7820A gas chromatograph equipped with an HP-5 capillary column $30 \mathrm{~m}$ $\times 0.32 \mathrm{~mm} \times 0.25 \mu \mathrm{m}$ and a flame ionization detector. GC-MS analyses were performed on an Agilent 7890A gas chromatograph equipped with an HP-5 capillary column interfaced with an Agilent 5975C mass spectrometer. NMR spectra were taken on BrukerDPX300 and DPX400 spectrometers using standard conditions. Electrospray ionization mass spectrometry (ESI-MS) experiments were performed on a Bruker Daltonics Esquire 3000 Spectrometer using a $1 \mathrm{mM}$ solution of the analyzed compound. Elemental analyses were performed using a CHNS-O EA-1108 elemental analyzer from Fisons.

\subsection{Synthesis of Complex 17}

In the glovebox, 2,2'-bipyridine $(28.0 \mathrm{mg}, 0.18 \mathrm{mmol})$ was dissolved in acetonitrile ( $2 \mathrm{~mL}$ ). Then $\mathrm{Mn}(\mathrm{OTf}){ }_{2}(31.7 \mathrm{mg}, 0.09$ mmol) was added directly as a solid and the mixture was stirred overnight. Afterward the solution was filtered over Celite. Slow diethyl ether diffusion over the resulting solution in the anaerobic box afforded $43.8 \mathrm{mg}$ (73\% yield) of yellow crystals. ESI-MS $(\mathrm{m} / \mathrm{z}):\left[\mathrm{Mn}(\mathrm{bpy})_{2}\right]^{2+}:$ 183.5. Anal. Calcd for $\mathrm{C}_{22} \mathrm{H}_{16} \mathrm{~F}_{6} \mathrm{MnN}_{4} \mathrm{O}_{6} \mathrm{~S}_{2}$ : C, 39.71; H, 2.42; N, 8.42. Found: C, 39.70; H, 2.41; N, 8.81.

\subsection{Oxidation Protocol}

A solution $(2 \mathrm{~mL})$ of the substrate $(0.1-0.5 \mathrm{M})$ and the pertinent complex $(1.0 \mathrm{mM})$ was prepared in a vial $(10 \mathrm{~mL})$ equipped with a stirring bar using the desired solvent (acetonitrile or 2,2,2-trifluoroethanol). When used, acetic acid (2.0 equiv.) in the appropriate solvent was added to the reaction mixture. Then, hydrogen peroxide ( $0.2-1.0$ equiv.) or peracetic acid ( 0.2 equiv) in the appropriate solvent was added by syringe pump over a period of 30 or $10 \mathrm{~min}$, respectively. Afterwards, the solution was stirred for further 30 or $50 \mathrm{~min}$, respectively. At this point, an internal standard was added and the solution was quickly filtered through a silica plug, which was subsequently rinsed with $2 \times 1 \mathrm{~mL}$ AcOEt. GC analysis of the solution provided product yields relative to the internal standard. Calibration curves for products $\mathbf{1 a}-\mathbf{d}$ were obtained using commercially available pure compounds. Calibration curve for product $\mathbf{2 b}$ was obtained using the pure synthetized compound.

\section{Acknowledgements}

The authors thank the Spanish Ministry of Science (CTQ201570795-P to M.C., CTQ2016-77989-P to A.C.), Generalitat de Catalunya (ICREA Academia Award to M.C. and 2014 SGR 862) and the European Commission through the NoNoMeCat project (675020-MSCA-ITN2015-ETN) for financial support.

\section{Supplementary Information}

Supplementary information is available on https://www.ingentaconnect.com/content/scs/chimia

Received: April 20, 2020

[1] A. J. L. Pombeiro, M. de Fatima Costa Guedes da Silva, 'Alkane Functionalization', Wiley, 2019.

[2] J. F. Hartwig, M. A. Larsen, ACS Cent. Sci. 2016, 2, 281.

[3] K. Godula, D. Sames, Science 2006, 312, 67.

[4] G. Olivo, O. Cussó, M. Borrell, M. Costas, J. Biol. Inorg. Chem. 2017, 22, 425.

[5] M. C. White, J. Zhao, J. Am. Chem. Soc. 2018, 140, 13988.

[6] W. N. Oloo, L. Que, Acc. Chem. Res. 2015, 48, 2612.

[7] Z. Codola, J. Lloret-Fillol, M. Costas, 'Aminopyridine Iron and Manganese Complexes as Molecular Catalysts for Challenging Oxidative Transformations', in 'Progress in Inorganic Chemistry: Volume 59', Ed. K. D. Karlin, Wiley, 2014

[8] K. P. Bryliakov, E. P. Talsi, Coord. Chem. Rev. 2014, 276, 73.
[9] R. V. Ottenbacher, E. P. Talsi, K. P. Bryliakov, Chem. Rec. 2018, 18, 78.

[10] W. Sun, Q. Sun, Acc. Chem. Res. 2019, 52, 2370.

[11] M. Guo, T. Corona, K. Ray, W. Nam, ACS Cent. Sci. 2019, 5, 13.

[12] A. C. Lindhorst, S. Haslinger, F. E. Kühn, Chem. Commun. 2015, 51, 17193

[13] P. Saisaha, J. W. de Boer, W. R. Browne, Chem. Soc. Rev. 2013, 42, 2059.

[14] G. Olivo, O. Lanzalunga, S. Di Stefano, Adv. Syn. Catal. 2016, 358, 843.

[15] T. Newhouse, P. S. Baran, Angew. Chem. Int. Ed. 2011, 50, 3362.

[16] I. Prat, L. Gómez, M. Canta, X. Ribas, M. Costas, Chem. Eur. J. 2013, 19, 1908.

[17] M. S. Chen, M. C. White, Science 2010, 327, 566.

[18] L. Gómez, M. Canta, D. Font, I. Prat, X. Ribas, M. Costas, J. Org. Chem. 2013, 78, 1421.

[19] P. E. Gormisky, M. C. White, J. Am. Chem. Soc. 2013, 135, 14052.

[20] D. Shen, C. Miao, S. Wang, C. Xia, W. Sun, Org. Lett. 2014, 16, 1108.

[21] R. V. Ottenbacher, D. G. Samsonenko, E. P. Talsi, K. P. Bryliakov, Org. Lett. $2012,14,4310$.

[22] K. Nehru, S. J. Kim, I. Y. Kim, M. S. Seo, Y. Kim, S.-J. Kim, J. Kim, W. Nam, Chem. Commun. 2007, 4623.

[23] W. Wang, D. Xu, Q. Sun, W. Sun, Chem. Asian J. 2018, 13, 2458.

[24] P. Saisaha, J. J. Dong, T. G. Meinds, J. W. de Boer, R. Hage, F. Mecozzi, J. B. Kasper, W. R. Browne, ACS Catal. 2016, 6, 3486.

[25] P. Saisaha, L. Buettner, M. van der Meer, R. Hage, B. L. Feringa, W. R. Browne, J. W. de Boer, Adv. Syn. Catal. 2013, 355, 2591.

[26] Y. Hitomi, K. Arakawa, M. Kodera, Chem. Eur. J. 2013, 19, 14697.

[27] S. Jana, M. Ghosh, M. Ambule, S. Sen Gupta, Org. Lett. 2017, 19, 746.

[28] L. Ma, Y. Pan, W.-L. Man, H.-K. Kwong, W. W. Y. Lam, G. Chen, K.-C. Lau, T.-C. Lau, J. Am. Chem. Soc. 2014, 136, 7680.

[29] I. Ghosh, S. Banerjee, S. Paul, T. Corona, T. K. Paine, Angew. Chem. Int. Ed. 2019, 58,12534

[30] M. Mitra, J. Lloret-Fillol, M. Haukka, M. Costas, E. Nordlander, Chem. Commun 2014, 50, 1408.

[31] G. Roelfes, M. Lubben, R. Hage, J. Que, Lawrence, B. L. Feringa, Chem. Eur. J. 2000, 6, 2152.

[32] K. Chen, L. Que, J. Am. Chem. Soc. 2001, 123, 6327.

[33] G. V. Nizova, B. Krebs, G. Süss-Fink, S. Schindler, L. Westerheide, L. Gonzalez Cuervo, G. B. Shul'pin, Tetrahedron 2002, 58, 9231.

[34] G. B. Shul'pin, G. V. Nizova, Y. N. Kozlov, L. Gonzalez Cuervo, G. SüssFink, Adv. Syn. Catal. 2004, 346, 317.

[35] V. B. Romakh, B. Therrien, G. Süss-Fink, G. B. Shul'pin, Inorg. Chem. 2007, 46, 3166

[36] E. V. Kudrik, P. Afanasiev, L. X. Alvarez, P. Dubourdeaux, M. Clémancey, J.-M. Latour, G. Blondin, D. Bouchu, F. Albrieux, S. E. Nefedov, A. B. Sorokin, Nat. Chem. 2012, 4, 1024.

[37] A. B. Sorokin, E. V. Kudrik, D. Bouchu, Chem. Commun. 2008, 2562.

[38] Y. Morimoto, Y. Shimaoka, Y. Ishimizu, H. Fujii, S. Itoh, Angew. Chem. Int. Ed. 2019, 58, 10863

[39] S. T. Kleespies, W. N. Oloo, A. Mukherjee, L. Que, Inorg. Chem. 2015, 54, 5053.

[40] C.-W. Tse, T. W.-S. Chow, Z. Guo, H. K. Lee, J.-S. Huang, C.-M. Che, Angew. Chem. Int. Ed. 2014, 53, 798.

[41] A. Murphy, A. Pace, T. D. P. Stack, Org. Lett. 2004, 6, 3119.

[42] A. M. Adams, J. Du Bois, H. A. Malik, Org. Lett. 2015, 17, 6066.

[43] R. A. Moretti, J. Du Bois, T. D. P. Stack, Org. Lett. 2016, 18, 2528.

[44] D. H. R. Barton, D. Doller, Acc. Chem. Res. 1992, 25, 504.

[45] P. Stavropoulos, R. Çelenligil-Çetin, A. E. Tapper, Acc. Chem. Res. 2001, 34, 745 .

[46] A. Company, G. Sabenya, M. González-Béjar, L. Gómez, M. Clémancey, G. Blondin, A. J. Jasniewski, M. Puri, W. R. Browne, J.-M. Latour, L. Que, M. Costas, J. Pérez-Prieto, J. Lloret-Fillol, J. Am. Chem. Soc. 2014, 136, 4624.

[47] Z. Codolà, I. Gamba, F. Acuña-Parés, C. Casadevall, M. Clémancey, J.-M. Latour, J. M. Luis, J. Lloret-Fillol, M. Costas, J. Am. Chem. Soc. 2019, 141, 323.

[48] J. Chen, R. J. M. Klein Gebbink, ACS Catal. 2019, 9, 3564

[49] S. Tanaka, Y. Kon, T. Nakashima, K. Sato, RSC Adv. 2014, 4, 37674.

[50] M. S. Chen, M. C. White, Science 2007, 318, 783.

[51] M. C. White, A. G. Doyle, E. N. Jacobsen, J. Am. Chem. Soc. 2001, 123, 7194.

[52] M. Mitra, H. Nimir, D. A. Hrovat, A. A. Shteinman, M. G. Richmond, M. Costas, E. Nordlander, J. Mol. Catal. A 2017, 426, 350.

[53] V. Dantignana, M. Milan, O. Cussó, A. Company, M. Bietti, M. Costas, ACS Cent. Sci. 2017, 3, 1350

[54] E. Gaster, S. Kozuch, D. Pappo, Angew. Chem. Int. Ed. 2017, 56, 5912.

[55] M. Salamone, M. Bietti, Acc. Chem. Res. 2015, 48, 2895.

[56] M. Salamone, M. Bietti, Synlett 2014, 25, 1803.

[57] M. Costas, A. K. Tipton, K. Chen, D.-H. Jo, L. Que, J. Am. Chem. Soc. 2001, 123,6722 .

[58] O. Cussó, I. Garcia-Bosch, X. Ribas, J. Lloret-Fillol, M. Costas, J. Am. Chem. Soc. 2013, 135, 14871.

[59] D. Font, M. Canta, M. Milan, O. Cussó, X. Ribas, R. J. M. Klein Gebbink, M. Costas, Angew. Chem. Int. Ed. 2016, 55, 5776.

[60] A. Murphy, G. Dubois, T. D. P. Stack, J. Am. Chem. Soc. 2003, 125, 5250. 
[61] R. V. Ottenbacher, K. P. Bryliakov, E. P. Talsi, Adv. Syn. Catal. 2011, 353, 885

[62] O. Cussó, I. Garcia-Bosch, D. Font, X. Ribas, J. Lloret-Fillol, M. Costas, Org. Lett. 2013, 15, 6158.

[63] M. Milan, M. Bietti, M. Costas, ACS Cent. Sci. 2017, 3, 196.

[64] A. Company, L. Gómez, M. Güell, X. Ribas, J. M. Luis, L. Que, M. Costas, J. Am. Chem. Soc. 2007, 129, 15766.

[65] I. Garcia-Bosch, A. Company, X. Fontrodona, X. Ribas, M. Costas, Org. Lett. 2008, 10, 2095.

[66] Ö. Tamer, D. Avcı, Y. Atalay, B. Çosut, Y. Zorlu, M. Erkovan, Y. Yerli, J. Mol. Struct. 2016, 1106, 98

[67] L. A. Paquette, G. D. Parker, T. Tei, S. Dong, J. Org. Chem. 2007, 72, 7125.

[68] R. Giri, Y. Lan, P. Liu, K. N. Houk, J.-Q. Yu, J. Am. Chem. Soc. 2012, 134, 14118.

[69] K. U. Ingold, D. C. Nonhebel, J. C. Walton, J. Phys. Chem. 1986, 90, 2859.

[70] D. Nitsch, S. M. Huber, A. Pöthig, A. Narayanan, G. A. Olah, G. K. S Prakash, T. Bach, J. Am. Chem. Soc. 2014, 136, 2851.
License and Terms

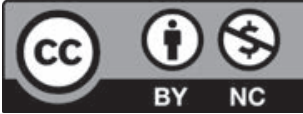

This is an Open Access article under the terms of the Creative Commons Attribution License CC BY_NC 4.0. The material may not be used for commercial purposes.

The license is subject to the CHIMIA terms and conditions: (http:// chimia.ch/component/sppagebuilder/?view=page \&id=12).

The definitive version of this article is the electronic one that can be found at doi:10.2533/chimia.2020.470. 